\title{
Socioeconomic status, time preferences and pro-environmentalism
}

\author{
Aurore Grandin*1, Léonard Guillou ${ }^{2}$, Rita Abdel Sater ${ }^{1}$, Martial Foucault ${ }^{3}$, \\ and Coralie Chevallier ${ }^{1}$ \\ ${ }^{1}$ Laboratoire de neurosciences cognitives et computationnelles, Département d'études cognitives, Ecole \\ normale supérieure, Université PSL, INSERM, 75005 Paris, France \\ ${ }^{2}$ Institut Jean Nicod, Département d'études cognitives, Ecole normale supérieure, Université PSL, \\ EHESS, CNRS, 75005 Paris, France \\ ${ }^{3}$ Centre de recherches politiques (CEVIPOF), Sciences Po, CNRS, 75006 Paris, France
}

February 2022

\begin{abstract}
Future-oriented individuals tend to display more pro-environmental attitudes and behaviours, compared to those who are present-oriented. Investigating the determinants of time preferences could therefore shed light on factors that also influence environmentalism. A key factor that impacts time preferences is socioeconomic status (SES). Importantly, SES is also positively correlated with willingness to act for the environment. In this paper, we test whether time preferences partially mediate the relationship between SES and pro-environmentalism in three studies. In the first study, we tested the assumption that pro-environmental attitudes are positively correlated with SES on a large cross-sectional French sample (N $=15,924)$. We found expected results both with an objective and a subjective measure of SES. Then, we conducted an online study including a temporal discounting task, which allowed us to fully test the mediation hypothesis on British participants $(\mathrm{N}=650)$. Our results suggest that the positive association between SES and pro-environmental attitudes is partially mediated by temporal discounting, but no significant mediated relationship was found for pro-environmental behaviour. Finally, we conducted a third study with an experimental setting, for which we recruited British participants who underestimated their position in the income distribution $(\mathrm{N}=855)$. In the treatment group, participants received a correction of their misperception, in order to increase their perceived relative income. Although the expected shift towards increased preferences for the future was not observed, we found a moderated effect of the treatment on pro-environmentalism.
\end{abstract}

Keywords: Socioeconomic status; Pro-environmental behaviour; Environmental attitudes; Temporal discounting; Perceived relative affluence.

\footnotetext{
${ }^{*}$ Correspondence should be sent to Aurore Grandin, Laboratoire de neurosciences cognitives et computationnelles, Département d'études cognitives, Ecole normale supérieure, Université PSL, INSERM, 75005 Paris, France. E-mail address: aurore.grandin@ens.psl.eu
} 


\section{Introduction}

Environmental issues are emblematic cases of intertemporal problems: they involve resource dilemmas where a short-term cost is incurred for a benefit that only comes in the future (Kortenkamp and Moore, 2006). Preserving forests or fresh water for example, yields immediate costs, such as refraining from using a resource that is available, while the majority of the benefits are only felt in the future. Cutting one's individual carbon emissions by limiting the use of one's car or reducing heating at home also implies self-restraint in the present, in order to maintain decent life conditions for future generations, or for oneself in the future.

Given the temporal nature of environmental issues, individual variations in time preferences may have an effect on people's willingness to engage in environmental actions (Van Vugt et al., 2014). In line with this idea, a meta-analysis by Milfont et al. (2012) shows that there is a link between time orientation and pro-environmental attitudes and behaviour, such that individuals with a future-oriented time perspective are on average more engaged in environmental preservation than present-oriented individuals. Identifying the factors that influence time preferences is therefore of central importance to shed light on the variability of pro-environmental attitudes and behaviour.

Several socio-demographic factors play a role in explaining variations in time preferences (Reimers et al., 2009). In particular, multiple studies have now demonstrated that low socioeconomic status (SES) orients individual time preferences towards the present, resulting in a tendency to favour short-term behaviours. Time preferences are typically measured using temporal discounting tasks, in which participants are asked to choose between smaller, more immediate rewards, and larger but more delayed rewards (Frye et al., 2016; Green et al., 1994). Using these tasks, researchers have shown that people with low incomes and educational levels discount more steeply than people with a higher SES (Enzler et al., 2014; Green et al., 1996; Harrison et al., 2002; Hausman, 1979; Lawrance, 1991; Reimers et al., 2009). Research documenting increases in impatience due to natural disasters and climate-driven income shocks provides support to the hypothesis that this association between SES and time preferences is causal (Cassar et al., 2017; Di Falco et al., 2019; Tanaka et al., 2010). These empirical results are congruent with recent theoretical papers arguing that differences in time preferences play an important role in accounting for socioeconomic gradients in a range of individual behaviours (Bickel et al., 2014; Mani et al., 2013; Pepper and Nettle, 2017; Sheehy-Skeffington and Rea, 2017).

Given that socioeconomic conditions have an impact on time preferences on the one hand, and given that future-oriented individuals tend to engage more in proenvironmental actions on the other, SES may have an effect on pro-environmental behaviour via time preferences. In line with this idea, social scientists have long noted an association between SES and pro-environmental attitudes and behaviour in large-scale reviews (Diamantopoulos et al., 2003; Hines et al., 1987). More recent research confirms that green consumption, recycling, signing petitions, or engaging in environmental organisations are more widespread among high SES individuals (Guerin et al., 2001; Kennedy et al., 2018; Kennedy and Givens, 2019), and multilevel analyses have shown that this pattern is found in countries around the world (Franzen and Meyer, 2009; Haller and Hadler, 2008; Marquart-Pyatt, 2008; Pisano and Lubell, 2017). Other studies have found that despite the fact that individuals 
of lower SES are more worried about the risks associated with environmental hazards, they report being less willing to act for the environment than individuals with higher incomes and educational attainments (Lo, 2016; Marquart-Pyatt, 2012).

Financial capacities play a direct and rather obvious role in this association, because many pro-environmental behaviours are costly. For example, having more money decreases the relative burden of green taxes and facilitates access to ecofriendly products. Symmetrically, pro-environmental behaviours that are cost-effective, such as energy-saving behaviours and the use of public transport, are more frequent among low SES individuals (Blankenberg and Alhusen, 2018; Trotta, 2018). This mechanical effect of income is however limited. Prior research has pointed out that the association between pro-environmentalism and income is quite small (Hines et al., 1987), and that education level is a stronger and more systematic predictor (Blankenberg and Alhusen, 2018; Lo, 2016; Marquart-Pyatt, 2012; Pearson et al., 2017). Engagement in pro-environmental behaviour is also influenced by other factors associated with SES. For instance, social scientists and economists have shown that green consumption is also a matter of signalling affiliation to a high social class (Delgado et al., 2015; Kennedy and Givens, 2019; van der Wal et al., 2016).

The goal of our paper is to test whether psychological preferences also contribute to the association between SES and pro-environmental behaviour. Recent theoretical frameworks, such as the one proposed by Pepper and Nettle (2017), indeed emphasize the role of time preferences in creating social gradients in a range of real-life decisions that have a strong temporal component, such as investment in education or preventive health. However, these theories have not been applied to environmental behaviour yet, and the idea that the relationship between SES and pro-environmentalism is mediated by time preferences has not been tested.

In this paper, our general hypothesis is that pro-environmental behaviour and willingness to protect the environment are less common among people with a lower SES in part because their temporal discounting is higher. In other words, we hypothesize that the relationship between SES and pro-environmental behaviour is partially mediated by temporal discounting. In our first study, we leverage existing data collected on a French large-scale sample to test the association between SES and pro-environmental attitudes. Our second study tests a mediation model between SES, pro-environmentalism and temporal discounting. Finally, our third study investigates the causal impact of an information shock about relative income on temporal discounting and pro-environmentalism.

\section{Study 1}

In study 1, we capitalized on existing data collected by the Center of political research of Sciences Po (CEVIPOF) from a large sample of the French population. We examined whether SES was associated with pro-environmental attitudes. Before analysing the data, our hypotheses, methods, and analysis plan were pre-registered in the Open Science Framework (OSF): https://osf .io/qav9x. 


\subsection{Materials and Methods}

\subsubsection{Participants}

The original dataset contains 17 survey waves, ranging from November 2015 to November 2017. For the purposes of this study, we focused on data regarding respondents' environmental attitudes and merged them with information about respondents' SES. The final analysis includes participants with complete data for environmental and socioeconomic variables up to wave $8(\mathrm{~N}=17,070)$. Following our pre-registered exclusion criterion, we excluded 1,132 respondents who had answered "I don't know" to the environmental items. 14 participants who had answered "I don't know" to the household income question were also excluded (this exclusion criterion had been forgotten in the pre-registration, but matches the one used for the environmental variables). This resulted in a final dataset of 15,924 participants, with $55.7 \%$ women and age range $=16-97$ years $(\mathrm{M}=47.33, \mathrm{SD}=15.32)$. Mean monthly income was comprised between $€ 2,250$ and $€ 2,999$ and $53 \%$ of the sample had a higher education degree.

\subsubsection{Measures}

\section{- Socioeconomic Status}

Objective SES was assessed using level of education and monthly net household income, z-transformed and summed (correlation between income and education: $\mathrm{r}=0.22, p<.001)$. Subjective SES was assessed using z-transformed perceived financial ease, measured with a single item asking respondents how they were doing with their household income. Subjective perception of one's SES plays an important role in predicting disparities in many life domains (Kraus and Stephens, 2012). For example, several medical studies have shown that the association between subjective SES and health outcomes persists after controlling for education and income (Cené et al., 2016; Ghaed and Gallo, 2007). All the original questions in French, their English translation and the waves during which they were collected are available in the OSF-folder for this study (https://osf.io/9ube8/).

\section{- Environmental attitudes}

Pro-environmentalism was measured with the following survey question: "How important are the following issues to you personally? 1) health insurance, 2) social welfare, 3) pensions, 4) fighting unemployment, 5) purchasing power, 6) crime, 7) the environment, 8) immigration, 9) terrorism, 10) the European Union, 11) the competitiveness of companies established in France". This question was asked in wave 8 and in a couple of later waves. Since attrition grows from one wave to the next, we focused on wave 8 , which provides the largest sample for this question. To compute participants' pro-environmentalism, we built a score that captures their interest in environmental issues (as measured by item 7), relative to their overall interest in social and political matters (as measured by all items combined). For each participant, the pro-environmentalism score therefore corresponds to a ratio of the raw score in response to issue 7 over the mean of the scores provided on all issues. This transformation was added because raw responses to item 7 confound participants' general interest for political matters and their specific interest for the environment, which is the construct we ultimately care about. 
Willingness to increase green taxes and public spending. We also looked at items measuring people's willingness to increase public spending for the environment, to fight climate change and their willingness to increase taxes on polluting activities (see the OSF-folder: https://osf.io/9ube8/). These items were pre-registered as secondary outcomes, because we reasoned that questions relative to public spending and taxes are more likely to be confounded by political orientation than questions tapping general pro-environmental attitudes.

All items were rated on a five-point scale. They were z-transformed and coded so that the highest scores indicated a pro-environmental position. All three items relative to public spending and taxes were then summed to create a composite score measuring "willingness to increase green taxes and public spending" ( $\alpha=.73$, inter-item correlation $=0.47)$.

\section{$2.2 \quad$ Statistical analyses}

Our main analyses were pre-registered and carried out in $\mathrm{R}$. We conducted simple linear regressions, with the following specification:

Environmental attitudes ${ }_{i}=\beta_{0}+\beta_{1} S E S_{i}+\epsilon$

The associations between the environmental variables and objective and subjective SES were assessed separately with this same linear model. In addition, to control for the effect of political orientation and other potentially confounding variables, we also conducted supplementary unregistered analyses, with the following specification:

Environmental attitudes $_{i}=\beta_{2}+\beta_{3} S E S_{i}+\beta_{4}$ Age $_{i}+\beta_{5}$ Gender $_{i}+\beta_{6}$ Political position $_{i}+\epsilon$

Participants' political position was measured with a question that asked them to indicate where they stood on a scale of 0 to 10 , where 0 is left and 10 is right.

\subsection{Results}

Pro-environmentalism was positively and significantly associated with objective SES $(\beta=0.09, p<.001)$ and subjective SES $(\beta=0.07, p<.001$, see Table 1$)$. There was also a positive association between SES and willingness to increase green taxes and public spending (objective SES: $\beta=0.06, p<.001$; subjective SES: $\beta=0.04$, $p<.001$, see Table 1 ). Both environmental variables remained positively correlated with SES when controlling for age, gender and political orientation (see Table 3 in the Supplementary Materials).

The results obtained with education and income as separate variables can be found in the correlation matrix in the Supplementary Materials (see Table 2). Both pro-environmentalism and willingness to increase green taxes and public spending were correlated with educational level, but only pro-environmentalism was significantly correlated with income. Further analyses indicated that the different items that make up the composite willingness score were all positively correlated with education, but that their relationships with income were inconsistent: willingness to 
increase public spending for the environment was negatively correlated with income $(\mathrm{r}=-0.024, p=.002)$ and willingness to increase public spending to fight climate change was not correlated with income $(\mathrm{r}=-0.006, p=.413)$. Only willingness to increase taxes on polluting activities was positively correlated with both income ( $\mathrm{r}$ $=0.042, p<.001)$ and education $(\mathrm{r}=0.083, p<.001)$.

Table 1: Relationships between environmental attitudes and socioeconomic status

\begin{tabular}{|c|c|c|}
\hline & \multicolumn{2}{|c|}{ Dependent variable: } \\
\hline & $\begin{array}{c}\text { Pro-environmentalism } \\
(1) \\
\end{array}$ & $\begin{array}{l}\text { Willingness to increase green } \\
\text { taxes and spending } \\
(2)\end{array}$ \\
\hline Objective SES & $\begin{array}{c}0.09^{* * *} \\
(0.08,0.11)\end{array}$ & $\begin{array}{c}0.06^{* * *} \\
(0.04,0.07)\end{array}$ \\
\hline Intercept & $\begin{array}{c}0.00 \\
(-0.02,0.02)\end{array}$ & $\begin{array}{c}0.00 \\
(-0.02,0.02)\end{array}$ \\
\hline $\begin{array}{l}\text { Observations } \\
\text { Adjusted } \mathrm{R}^{2} \\
\mathrm{RSE}(\mathrm{df}=15922) \\
\text { F Statistic }(\mathrm{df}=1 ; 15922)\end{array}$ & $\begin{array}{c}15,924 \\
0.01 \\
1.00 \\
135.19^{* * *}\end{array}$ & $\begin{array}{c}15,924 \\
0.003 \\
1.00 \\
52.96^{* * *}\end{array}$ \\
\hline Subjective SES & $\begin{array}{c}0.07^{* * *} \\
(0.05,0.08)\end{array}$ & $\begin{array}{c}0.04^{* * *} \\
(0.03,0.06)\end{array}$ \\
\hline Intercept & $\begin{array}{c}-0.00 \\
(-0.02,0.02)\end{array}$ & $\begin{array}{c}0.00 \\
(-0.02,0.02)\end{array}$ \\
\hline $\begin{array}{l}\text { Observations } \\
\text { Adjusted } \mathrm{R}^{2} \\
\mathrm{RSE}(\mathrm{df}=15922) \\
\text { F Statistic }(\mathrm{df}=1 ; 15922)\end{array}$ & $\begin{array}{c}15,924 \\
0.005 \\
1.00 \\
74.31^{* * *}\end{array}$ & $\begin{array}{c}15,924 \\
0.002 \\
1.00 \\
31.60^{* * *}\end{array}$ \\
\hline
\end{tabular}

Note: OLS regression coefficients. Confidence intervals in parentheses. $\dagger \mathrm{p}<0.1 ;{ }^{*} \mathrm{p}<0.05$; ${ }^{* *} \mathrm{p}<0.01 ;{ }^{* * *} \mathrm{p}<0.001$. This table estimates the association between SES and two environmental outcome variables. Objective $S E S$ is a composite score combining education and income. Subjective SES is a rating of perceived financial ease. Pro-environmentalism measures the relative importance of the environment compared to other socio-political issues. Willingness to increase green taxes and public spending is a composite score combining participants' willingness to increase public spending for the environment, to fight climate change and to increase taxes on polluting activities. See detailed definitions for each variable in subsection 2.1.2.

\subsection{Discussion}

In this study, we found that participants' level of pro-environmentalism relative to other socio-political issues was significantly correlated with their SES. There was also a positive association between SES and willingness to increase green taxes and public spending. Globally, these results suggest that willingness to act for the environment is stronger among higher SES individuals. 
Arguably, a measure of willingness to increase green taxes and public spending is not strictly equivalent to willingness to act for the environment. The positive correlation between SES and willingness to increase green taxes and public spending could be partly due to the fact that richer individuals have a higher acceptance of taxes, simply because they have higher financial capacities. Supporting this view, a recent survey conducted with a representative sample of French adults indicates that low-income individuals are more likely to think that taxes are too high, compared to high-income individuals (Forsé and Parodi, 2015).

However, the present study provides evidence that the association between environmental attitudes and SES is not only a matter of willingness to pay and tax acceptance: the positive correlation between SES and pro-environmentalism suggests that, in France at least, higher SES individuals also give higher priority to environmental issues compared to other socio-political issues, such as health insurance or immigration.

On the whole, these analyses provide support for our hypothesis, but they are only a first step, since they are not sufficient to test the entire mediation model. We were limited by the dataset, which contained no measure of time preferences. In addition, there was no behavioural data, and the environmental variables were potentially confounded by financial and political factors. In study 2 , we test the mediation model using an online discounting task combined with relevant questionnaire data.

\section{$3 \quad$ Study 2}

The goal of Study 2 was to test whether time preferences partially mediate the relationship between SES and pro-environmental attitudes and behaviour. As in Study 1, our hypotheses, methods, and analysis plan were pre-registered (a first pre-registration focused on the replication of the association between SES and temporal discounting was made (https://osf.io/452zr) and a second pre-registration was added to specify our mediation hypotheses: https://osf.io/58rn2). Data, materials, and the $\mathrm{R}$ script used to analyse the data are also available in the OSFfolder for this study (https://osf.io/28zkg/files/).

Besides the measurement of time preferences, one important aspect of this second study is the use of a measure of pro-environmental behaviour. Even though environmental attitudes are good predictors of pro-environmental behaviour, important value-action gaps and intention-to-action gaps are widely documented (Kollmuss and Agyeman, 2002; Lavergne and Pelletier, 2015; Maki et al., 2019). Using direct measures of pro-environmental behaviour is therefore important to better understand the factors that influence actual decision-making (Clements et al., 2015; Oliphant et al., 2020).

\subsection{Materials and Methods}

\subsubsection{Participants}

We conducted a power analysis with $\mathrm{G}^{*}$ Power (version 3.1.9.3), which determined that a sample of at least 643 participants was sufficient to detect an effect size $f^{2}$ $=0.0122$ with $80 \%$ power. This effect size was computed based on the mean of two 
correlation coefficients reported by Reimers et al. (2009), who found a Spearman correlation of -0.09 between temporal discounting and income, and of -0.13 between temporal discounting and education. Participants were recruited via Prolific. Only British individuals with a minimum approval rate of $90 \%$ were eligible for our study. We recruited additional participants to compensate for attrition, resulting in a dataset of 765 participants.

Following our pre-registered exclusion criteria, we removed 9 participants who had failed one or more catch trials in the temporal discounting task. In addition, 49 participants who had responded too fast $(<500 \mathrm{~ms})$ or too slowly $(>2$ minutes) to single question screens, and 29 participants who responded too fast $(<3 \mathrm{~s})$ or too slowly ( $>5$ minutes) to the other survey pages were removed from our analyses. We also excluded 14 participants who did not provide their income. Finally, we added an unregistered exclusion criteria for participants who reported outlier income values $(\mathrm{N}=14)$. Personal monthly incomes above $£ 12,500$ were considered as likely reporting mistakes, and correspond to outlier data points (more than 2SD deviation from the mean).

Our final dataset includes 650 participants (70\% females) aged between 21 and 77 years $(\mathrm{M}=39$ years; $\mathrm{SD}=12.8)$. Participants had an average total monthly income of $£ 935$, ranging from $£ 0$ to $£ 12,000$ ( $S D=1,187$, see Table 2). Participants' educational level was quite high: only 17 participants did not finish high school, while $64 \%$ of them had either completed college or obtained a postgraduate degree.

\subsubsection{Measures}

We presented the questionnaire and discounting task using Qualtrics (https:// www.qualtrics.com). After providing informed consent, participants filled out the socio-demographic questionnaire. Then, they continued with the discounting task, followed by the measures of pro-environmental attitudes and behaviour.

\section{- Socioeconomic status}

Our measure of participants' objective $S E S$ was a single variable combining level of education and personal monthly income and benefits. We chose to ask respondents about their personal income rather than their household overall income because Micklewright and Schnepf (2010) have shown that questions about household income induce lower response rates and produce lower quality data. Participants were asked to report their personal monthly income in a free-text box, in order to avoid unintentional priming effects that can arise with the use of income brackets (Haisley et al., 2008). We also measured the total monthly amount of government benefits they received with a free-text box. Participants were asked to report their level of education on a 6-point scale. Income, benefits and level of education were ztransformed and summed to create the unique variable of objective SES (correlation between income and education: $\mathrm{r}=0.27, p<.001, \alpha=.40$ ).

As in the previous study, we included a measure of subjective SES, but this time we used a composite variable combining a scale from Griskevicius et al. (2013) and the MacArthur Scale of Subjective Social Status (a 10-rung ladder developed by Adler et al., 2000). Griskevicius et al.'s (2013) scale includes three items: In the past few years: (a) My family and I have had enough money for things, (b) I have lived in a relatively wealthy neighborhood, (c) I have felt relatively wealthy compared to other 
people in my neighborhood. A single index was obtained by summing individual scores across the three items $(\alpha=.68$, inter-item correlation $=.41)$. We adapted the MacArthur scale in the following way: "Think of this ladder as representing where people stand in the United Kingdom. At the top of the ladder are the people who are the best off, those who have the most money, most education, and best jobs. At the bottom are the people who are the worst off, those who have the least money, least education, and worst jobs or no job. Where would you place yourself on the ladder?". Participants' response to this scale and the index based on Griskevicius et al.'s (2013) scale were z-transformed and summed to create a unique variable of subjective SES. The correlation between these two combined measures was strong $(\mathrm{r}=0.59, p<.001)$. The detailed list of all socioeconomic variables is available in the OSF-folder for this study (https://osf.io/7v3hs/).

\section{- Pro-environmental attitudes}

Pro-environmental attitudes are multidimensional and there is a large number of measures in the literature. In an effort to synthesize these various scales, Milfont and Duckitt (2010) developed the Environmental Attitudes Inventory, which comprises twelve specific scales that capture the main dimensions highlighted by previous research, such as enjoyment of nature, environmental fragility or support for interventionist conservation policies. The present article focuses on attitudes related to willingness to act for the environment. In Study 2, we assessed these attitudes using two 10-item scales from the Environmental Attitudes Inventory (Environmental movement activism and Personal conservation behaviour). All items are listed in Table 1 in the Supplementary Materials.

\section{- Pro-environmental behaviour}

A donation question was included at the end of the experiment. We drew on recent works showing that a non-hypothetical donation to an environmental nonprofit organization is a valid measure of pro-environmental behaviour (Clements et al., 2015; Eby et al., 2019). Following Ackermann et al. (2014), we offered participants a choice between different charitable causes rather than specific nonprofit organizations, to avoid biased responses from individuals with strong feelings regarding a particular organization. The six different causes were presented in a random order to counter order effects. To avoid the bias that lower income participants have less money to give, we told participants that a donation would be made on their behalf to a cause of their choosing (see Eby et al., 2019). Participants were informed that we would give 10p to a charity for every person that participated in our study, and that they could choose their two favourite causes out of six options: Reforestation programmes, Food aid for the homeless, Medical cancer research, Care for the elderly, Emergency and disaster relief, Education in developing countries. Answers were transformed into a binary variable (presence of the cause "Reforestation programmes" among the two choices $=1$, absence $=0$ ).

\section{- Temporal discounting}

The temporal discounting task was based on Frye et al. (2016). Participants had to complete three blocks of an intertemporal choice task with varying delays and amounts. Each block consisted of six binary choice trials. The task ended with 
two catch trials, resulting in a total of 20 trials. In the first block, participants had the choice between a smaller reward in three days, and a larger reward in three weeks. In the second and third blocks, the later delay was set to three months and two years respectively. As in Haushofer et al. (2013), possible serial correlations and order effects in participants' responses were controlled for by randomising the order of trials across blocks. The position of the sooner smaller and larger later alternatives on the screen (top vs. bottom) was also randomised across trials to control for possible position effects.

The monetary choices presented to participants were hypothetical. One concern might be that they may not be sufficiently motivated to give thoughtful answers when answering hypothetical questions. However, no clear and systematic differences have been identified when comparing real and hypothetical rewards in discounting tasks (Coller and Williams, 1999; Johnson and Bickel, 2002; Kirby and Maraković, 1995). Moreover, discount rates measured with hypothetical choices in a laboratory setting have been found to correlate with real-world measures of impulsivity such as smoking, overeating, and debt repayment

y2013measure, meier2012time, Reimers2009.

The later reward was kept constant (at $70 £$ as in Reimers et al., 2009), while the smaller reward was adjusted according to participants' choices. The adjustment was based on a bisection algorithm, following Frye et al. (2016). As recommended by the authors, the adjustment for the upcoming trial was always equal to the maximum amount multiplied by $2^{(-n)}$, where $\mathrm{n}$ is the trial number for the current adjustment. Such a procedure allows for the identification of various individual indifference points for each participant. An indifference point corresponds to the magnitude of the smaller-sooner reward at which a participant shows no preference for either the smaller-sooner or later-larger reward (Scholten et al., 2019). It can be used for the computation of a discount rate.

The method that we chose to compute respondents' discount rates is based on the computation of the area under the curve (AUC) of the empirical discounting function (see Frye et al., 2016; Myerson et al., 2001). The empirical discounting function is defined by the various indifference points evidenced by the discounting task. The AUC between two points on the curve is calculated as $\left[\left(x_{2}-x_{1}\right)\left[\left(y_{1}+y_{2}\right) / 2\right]\right.$, where $x_{1}$ and $x_{2}$ are the successive delays and $y_{1}$ and $y_{2}$ are the indifference points for those delays. In the present study, the AUC between 3 weeks and 3 months and the one between 3 months and 2 years were summed, resulting in a single value of AUC per participant. Lower values of the AUC indicate a steeper discount rate.

\subsection{Statistical analyses}

Regression analyses were conducted relying on the three step procedure set forth by Baron and Kenny (1986) to detect a mediation effect. The regression models had the following specifications:

Environmentalism $=\beta_{10}+\beta_{11} S E S+\epsilon$

DiscountRate $=\beta_{12}+\beta_{13} S E S+\epsilon$

Environmentalism $=\beta_{14}+\beta_{15}$ SES $+\beta_{16}$ DiscountRate $+\epsilon$

Where Environmentalism refers alternatively to pro-environmental attitudes and behaviour; SES refers alternatively to objective or subjective SES; and Discount 
Rate corresponds to the area under the curve (AUC). We used an OLS regression model for every equation, except for pro-environmental behaviour, for which we used a Logit regression.

Following Baron and Kenny's (1986) approach, a mediation effect exists if coefficients $\beta_{11}$ and $\beta_{13}$ in equations (3) and (4) are significant, and if coefficient $\beta_{15}$ in equation (5) is not significant: in other words, there is a mediation when the predictor-outcome effect becomes non-significant once the mediator is added to the model. Partial mediation is established when the effect of the predictor on the outcome only weakens once the mediator is added. However, this approach does not formally test the significance of the mediating effect and does not assess its size. Researchers have recommended that other methods, such as nonparametric testing procedures, should be used for this purpose (Aguinis et al., 2016; Holmbeck, 2002; Preacher and Hayes, 2004). We derived percentile-based confidence intervals with the bootstrap, relying on R mediation package (see Tingley et al., 2014).

\subsection{Results}

Descriptive statistics for key variables are reported in Table 2. Tables 3 and 4 provide the regression and bootstrap estimates for the full model.

Table 2: Descriptive statistics

\begin{tabular}{lccccc}
\hline \hline Statistic & $\mathrm{N}$ & Mean & SD & Min & Max \\
\hline Education score & 650 & 3.67 & 1.07 & 1 & 5 \\
Income (£) & 650 & 935 & 1,187 & 0 & 12,000 \\
Benefits (£) & 650 & 113 & 256 & 0 & 1,595 \\
Griskevicius items & 650 & 12.04 & 3.61 & 3 & 21 \\
MacArthur Scale & 650 & 5.43 & 1.56 & 1 & 10 \\
AUC (temporal discounting) & 650 & 19,033 & 11,497 & 709 & 49,276 \\
Activism score & 650 & 4.45 & 1.11 & 1 & 6.8 \\
Conservation score & 650 & 5.17 & 0.95 & 2 & 7 \\
Pro-environmental behaviour & 650 & 0.27 & 0.45 & 0 & 1 \\
\hline
\end{tabular}

Note: Activism score and Conservation score refer to Milfont and Duckitt's (2010) scales from the Environmental Attitudes Inventory, which were used to calculate participants' proenvironmental attitudes. See detailed definition of each variable in subsection 3.1.2.

\section{Mediation analysis}

For the first step of the mediation analysis, environmental variables were regressed on socioeconomic variables. We found a positive and significant relationship between self-reported pro-environmental attitudes and SES (objective SES: $\beta$ $=0.09, p=.026$; subjective SES: $\beta=0.08, p=.035$, see Table 3 ). However, our measure of pro-environmental behaviour was not correlated with either objective or subjective SES (see Table 4 in the Supplementary Materials).

For the second step of the mediation analysis, we found the expected association between SES and temporal discounting: the area under the discounting curve was positively correlated with objective $(\beta=0.15, p<.001)$ and subjective SES $(\beta$ $=0.17, p<.001$, see Table 3 ). Since lower values of the area under the curve indicate steeper discounting, this means that participants with lower SES tended 
to discount more future rewards. Figure 1 illustrates these results for the objective variable: it represents the mean indifference points as a function of time for lowSES participants and high-SES participants (using a median split). The area under the discounting curve is smaller for low-SES participants, which reflects a steeper discount rate.

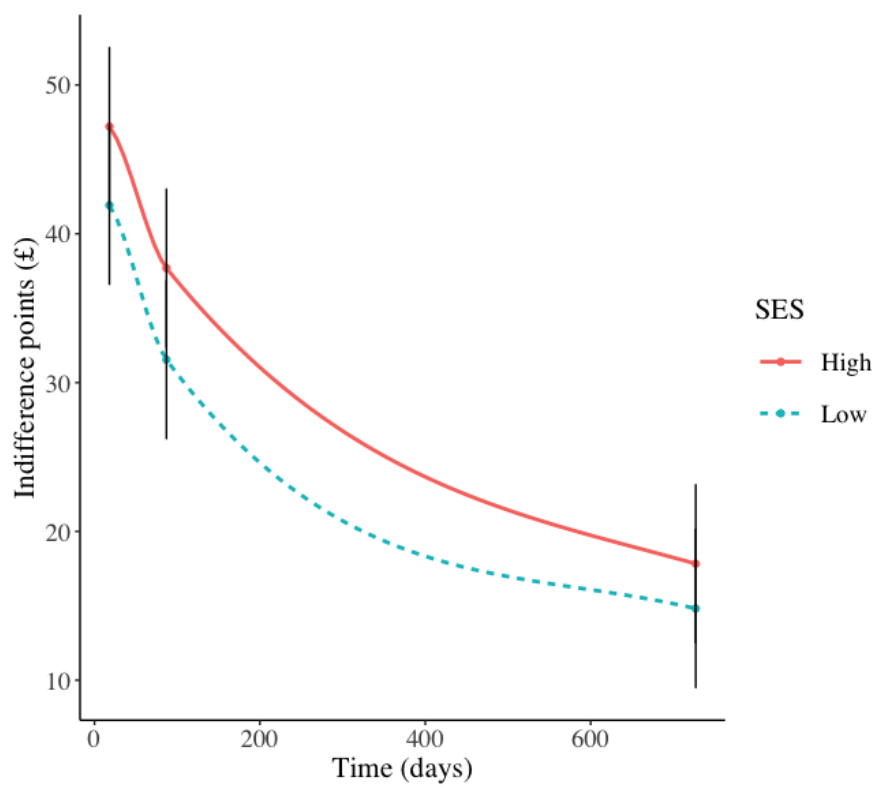

Figure 1: Area under the curve of high and low SES participants

This figure displays the mean indifference points as a function of time for high and low SES participants. Three indifference points are plotted on the graph, as the questionnaire contained three different delays. Error bars represent standard error of the mean.

The third step of the mediation analysis was consistent with our hypotheses, as far as pro-environmental attitudes are concerned: the positive association with objective SES disappeared when adding the temporal discounting variable to the regression model $(\beta=0.07, p=.095$, see Table 3$)$. We observed a similar pattern with subjective SES: its positive correlation with pro-environmental attitudes disappeared when the discounting variable was added to the model $(\beta=0.05, p=.141$, see Table 3), which is compatible with the hypothesis of a mediation. Controlling for gender and age, all of our linear models with SES and environmental variables yielded similar results, indicating that the associations that we observed were not driven by these other variables (see Table 5 in the Supplementary Materials).

\section{Size of the mediating effect}

To estimate the size of the hypothesized mediating effect and the direct effect, we computed nonparametric bootstrap confidence intervals with the percentile method, using R mediation package (Tingley et al., 2014). Concerning objective SES and pro-environmental attitudes, the average mediating effect was positive and significant $(\beta=0.031, p<.001)$ but the direct effect was stronger, albeit still small $(\beta=$ 
$0.093, p=.040$, see Table 4$)$. As could be expected from the regression analyses, we found no significant direct or mediated effect of objective and subjective SES on the behavioural measure using the bootstrap. Finally, the relationship between subjective SES and pro-environmental attitudes was significantly mediated by temporal discounting $(\beta=0.034, p<.001)$. There was also a direct effect but it was not significant $(\beta=0.081, p=0.114$, see Table 4$)$.

Table 3: Baron and Kenny's (1986) three step procedure

\begin{tabular}{|c|c|c|c|}
\hline & \multicolumn{3}{|c|}{ Dependent variable: } \\
\hline & $\begin{array}{l}\text { Pro-environmental attitudes } \\
\text { (1) }\end{array}$ & $\begin{array}{l}\text { AUC } \\
(2)\end{array}$ & $\begin{array}{c}\text { Pro-environmental attitudes } \\
\text { (3) }\end{array}$ \\
\hline Objective SES & $\begin{array}{c}0.09^{*} \\
(0.01,0.16)\end{array}$ & $\begin{array}{c}0.15^{* * *} \\
(0.08,0.23)\end{array}$ & $\begin{array}{c}0.07 \dagger \\
(-0.01,0.14)\end{array}$ \\
\hline AUC & & & $\begin{array}{c}0.14^{* * *} \\
(0.07,0.22)\end{array}$ \\
\hline Intercept & $\begin{array}{c}0.00 \\
(-0.08,0.08)\end{array}$ & $\begin{array}{c}0.00 \\
(-0.08,0.08)\end{array}$ & $\begin{array}{c}0.00 \\
(-0.08,0.08)\end{array}$ \\
\hline $\begin{array}{l}\text { Observations } \\
\text { Adjusted } \mathrm{R}^{2} \\
\text { RSE } \\
\text { F Statistic } \\
\end{array}$ & $\begin{array}{c}650 \\
0.01 \\
1.00(\mathrm{df}=648) \\
4.99^{*}(\mathrm{df}=1 ; 648)\end{array}$ & $\begin{array}{c}650 \\
0.02 \\
0.99(\mathrm{df}=648) \\
15.19^{* * *}(\mathrm{df}=1 ; 648)\end{array}$ & $\begin{array}{c}650 \\
0.02 \\
0.99(\mathrm{df}=647) \\
9.26^{* * *}(\mathrm{df}=2 ; 647)\end{array}$ \\
\hline Subjective SES & $\begin{array}{c}0.08^{*} \\
(0.01,0.16)\end{array}$ & $\begin{array}{c}0.17^{* * *} \\
(0.10,0.25)\end{array}$ & $\begin{array}{c}0.06 \\
(-0.02,0.14)\end{array}$ \\
\hline AUC & & & $\begin{array}{c}0.14^{* * *} \\
(0.07,0.22)\end{array}$ \\
\hline Intercept & $\begin{array}{c}0.00 \\
(-0.08,0.08)\end{array}$ & $\begin{array}{c}0.00 \\
(-0.08,0.08)\end{array}$ & $\begin{array}{c}0.00 \\
(-0.08,0.08)\end{array}$ \\
\hline Observations & 650 & 650 & 650 \\
\hline Adjusted $\mathrm{R}^{2}$ & 0.01 & 0.03 & 0.02 \\
\hline RSE & $1.00(\mathrm{df}=648)$ & $0.99(\mathrm{df}=648)$ & $0.99(\mathrm{df}=647)$ \\
\hline F Statistic & $4.47^{*}(\mathrm{df}=1 ; 648)$ & $19.65^{* * *}(\mathrm{df}=1 ; 648)$ & $8.94^{* * *}(\mathrm{df}=2 ; 647)$ \\
\hline
\end{tabular}

Note: OLS regressions. Confidence intervals in parentheses. $\dagger \mathrm{p}<0.1 ;{ }^{*} \mathrm{p}<0.05 ;{ }^{* *} \mathrm{p}<0.01 ;{ }^{* * *} \mathrm{p}<0.001$. This table contains the three regressions of Baron and Kenny's (1986) procedure, aimed at testing the partially mediated effect of SES on pro-environmental attitudes via temporal discounting (AUC). See detailed definitions for each variable in subsection 3.1.2.

In addition, we conducted unregistered analyses to test our mediation model with education and total income (a variable combining personal income and benefits) as separate variables. The results can be found in Table ?? in the Supplementary Materials. There was both a direct and a mediated effect of education on proenvironmental attitudes (direct: $\beta=0.084, p=.020$; mediated: $\beta=0.021, p$ 
$<.001)$. As for total income, there was a slightly smaller mediated effect ( $\beta=$ $0.017, p=.028)$ and no significant direct effect $(\beta=0.020, p=.724)$.

Table 4: Correlational mediation analysis based on bootstrapping

\begin{tabular}{|c|c|c|c|c|}
\hline \multirow[b]{2}{*}{ Type of SES } & \multicolumn{3}{|c|}{ Dependent variable: Pro-environmental attitudes } & \multirow[b]{2}{*}{$95 \%$ CI Upper } \\
\hline & Statistic & Estimate & 95\% CI Lower & \\
\hline \multirow{4}{*}{ Objective } & Average mediated effect & $0.031^{* * *}$ & 0.012 & 0.05 \\
\hline & Average direct effect & $0.093^{*}$ & 0.002 & 0.19 \\
\hline & Total effect & $0.123^{*}$ & 0.034 & 0.22 \\
\hline & Proportion mediated & $0.249^{*}$ & 0.083 & 0.89 \\
\hline \multirow{4}{*}{ Subjective } & Average mediated effect & $0.034^{* * *}$ & 0.013 & 0.06 \\
\hline & Average direct effect & 0.081 & -0.021 & 0.18 \\
\hline & Total effect & $0.115^{*}$ & 0.018 & 0.22 \\
\hline & Proportion mediated & $0.298^{*}$ & 0.084 & 1.61 \\
\hline & \multicolumn{3}{|c|}{ Dependent variable: Pro-environmental behaviour } & \\
\hline Type of SES & Statistic & Estimate & 95\% CI Lower & $95 \%$ CI Upper \\
\hline \multirow{4}{*}{ Objective } & Average mediated effect & 0.006 & -0.002 & 0.02 \\
\hline & Average direct effect & -0.037 & -0.083 & 0.01 \\
\hline & Total effect & -0.031 & -0.077 & 0.02 \\
\hline & Proportion mediated & -0.194 & -2.224 & 1.43 \\
\hline \multirow{4}{*}{ Subjective } & Average mediated effect & 0.006 & -0.002 & 0.02 \\
\hline & Average direct effect & -0.018 & -0.063 & 0.03 \\
\hline & Total effect & -0.012 & -0.058 & 0.04 \\
\hline & Proportion mediated & -0.535 & -4.555 & 3.11 \\
\hline
\end{tabular}

Note: correlational mediation analyses testing for the effect of objective and subjective SES on pro-environmental attitudes and behaviour via temporal discounting. Bootstrapbased coefficients and confidence intervals. $N=650$. Sampling iterations $=1000$. $\dagger$ $\mathrm{p}<0.1 ;{ }^{*} \mathrm{p}<0.05 ;{ }^{* *} \mathrm{p}<0.01 ;{ }^{* * *} \mathrm{p}<0.001$.

\subsection{Discussion}

In line with our hypothesis, we find that pro-environmental attitudes are associated both with objective and subjective SES and that this relationship is partially mediated by temporal discounting. However, this result does not translate to the pro-environmental behaviour measure.

Null results concerning this variable could be due either to a gap between attitudes and behaviour, or to certain shortcomings of the donation question that we used to measure behaviour. The low stakes (a donation of 10p) might have contributed to diminish the validity of this measure. It could also be due to some specificities of the answer options we offered: the donation question asked participants to evaluate the importance of an environmental cause with respect to others, which may depend on the participants' evaluations of the other causes as much as the environmental one. It is also possible that the actions we included were too specific or that participants were influenced by the fact that some of the actions could be located in the UK, while others were relevant for other countries (e.g. 
"Education in developing countries"). This measure should be modified so as to decide if its validity can be improved.

In addition, a major limitation of studies 1 and 2 is the use of cross-sectional data, with which we cannot establish causal processes definitively. Even though our significant results are encouraging, other causal models could underlie the correlations that were found. Experimental studies are therefore needed before we can claim that there is a causal effect of SES on pro-environmental attitudes which is mediated by temporal discounting.

\section{$4 \quad$ Study 3}

The goal of this third study is to go beyond correlations and test the causal influence of socioeconomic resources on people's temporal discounting and proenvironmentalism. The only way to act on people's objective SES is to change their income, educational level or occupation, which is obviously difficult in an experimental setting. However, brief psychological interventions such as priming can be used to alter perceptions of one's socioeconomic condition: for instance, Griskevicius et al. (2013) used recession cues to prime their participants with resource scarcity in a laboratory experiment. Another possibility is economic games, which allow experimenters to manipulate participants' perception of their economic resources through income shocks: for example, Haushofer et al. (2013) found that negative income shocks lead to an increase in temporal discounting, and that positive income shocks weakly decrease discount rates.

Other kinds of research have shown that it is possible to use information about income as an experimental treatment, so as to alter the perception of one's socioeconomic condition (Card et al., 2012; Cruces et al., 2013; Hvidberg et al., 2020; Karadja et al., 2015; Mijs and Hoy, 2021). Capitalizing on works demonstrating that faulty beliefs about one's own position in the national income distribution are common (see Fehr et al., 2019; Norton and Ariely, 2011; Norton et al., 2014), economists and psychologists have shown that informing people of their true position in the income distribution can have an impact on political attitudes. For instance, Cruces et al. (2013) found that Argentinian respondents who believed themselves to be relatively richer than they actually were demanded more redistribution, when provided with correct information. Karadja et al. (2015) found that a vast majority of Swedes believed that they were poorer than they actually were relative to others, and that correcting this misperception had an effect on participants' attitudes toward redistribution.

In this study, we use a treatment similar to Karadja et al.'s (2015): in order to induce variations in the perception of one's SES, we draw on this work by using an informational treatment, which corrects misperceptions about one's position in the national income distribution. Thus, instead of an income shock in an economic game, we made use of an information shock about relative income. For this experiment, we selected British individuals who believed themselves to be poorer than they actually were (relative to others), and provided them with information about their actual position in the national income distribution. The experiment only targeted participants who held a wrong negative bias about their socioeconomic position in society. For ethical reasons, participants who believed that they were richer than they actually were did not receive any correction. 
We reasoned that this positive information shock would be the psychological equivalent of an income shock. Our main hypothesis for this study is that a positive information shock about relative income decreases temporal discounting. As an exploratory hypothesis, we also predicted that the magnitude of the negative bias, and thus the intensity of the treatment, would moderate the effect of the information shock on temporal discounting (i.e. the bigger the negative bias, the stronger the effect of the treatment), in line with results from Karadja et al. (2015), who found an interaction between the magnitude of the bias and the effect of their treatment. In addition, we made cross-sectional hypotheses concerning the relationships between pro-environmental attitudes and behaviour, temporal discounting and SES, in order to replicate Study 2's results. All theses hypotheses, as well as our methods and analysis plan were pre-registered (https://osf.io/bf8jv).

\subsection{Materials and Methods}

\subsubsection{Participants}

Participants were recruited via Prolific, relying on pre-screening criteria to filter the participants by nationality and approval rate: only British participants with a minimum approval rate of $90 \%$ were recruited. We also excluded students because their reported income may not reflect their actual living standards: students may earn no income but receive parental support. For the power analysis, we used measures of temporal discounting from Study 2. G*Power indicated that 807 participants were needed to be able to detect a minimum effect of 0.2 with a power of $80 \%$. Adding $10 \%$ to compensate for attrition, we thus aimed to include at least 888 participants.

910 eligible participants (i.e. with a negative bias) took part in the study. Our pre-registered exclusion criteria were similar to those used in Study 2. We excluded 21 participants who responded too fast $(<500 \mathrm{~ms})$ or too slowly $(>2$ minutes $)$ to single question screens, and 16 participants who responded too fast $(<3 \mathrm{~s})$ or too slowly ( $>5$ minutes) to the other survey pages. 11 participants who failed one or more catch trials in the temporal discounting task were removed from the analyses. In addition, we removed 7 participants who reported a personal monthly income above $£ 12,500$, in order to avoid outliers or potential reporting mistakes. This resulted in a total of 855 participants in the final dataset ( $52 \%$ females), aged between 23 and 74 years $(\mathrm{M}=42$ years; $\mathrm{SD}=10.5)$. Participants' SES was higher than in the previous study: their average total monthly income was $£ 2,736$, ranging from $£ 0$ to $£ 12,000$ ( $\mathrm{SD}=1,258$, see Table 5 ). Only 2 participants did not finish high school and $80 \%$ of them had either completed college or obtained a postgraduate degree.

\subsubsection{Procedure}

After providing informed consent, participants first answered questions about their SES and demographic characteristics. These answers were then used to calculate whether and by how much participants underestimated or overestimated their relative position in the British income distribution. The survey stopped there for participants who estimated their position accurately or overestimated it (null or 
positive bias). Those who underestimated their position (negative bias) were randomly assigned to the treatment or control condition. In the treatment condition, participants were presented with a correction of their position in the British society. After this information treatment, the rest of the survey was identical for both groups, where all participants completed the temporal discounting task followed by the environmental attitudes scales. In addition, questions about social trust were added to provide data for another project (Guillou et al., 2021). The measure of proenvironmental behaviour came last. Randomisation checks demonstrated that the two groups were balanced on gender ratio, age, income, educational level, subjective SES and bias (see Table 8 in the Supplementary Materials).

\subsubsection{Measures}

To measure pro-environmental attitudes and temporal discounting, we used the same environmental scales (see Table 1 in the Supplementary Materials) and discounting task as in Study 2 (see subsection 3.1.2). Materials, as well as the data and the $\mathrm{R}$ scripts used to analyse the data can also be found in the OSF (https://osf.io/5sbmr/files/).

\section{- Socioeconomic Status}

Concerning SES, we used similar questions as in Study 2, with minor modifications to increase their accuracy and reliability. As for income, we used the same question but we added another one aimed at decreasing reporting error: participants' annual income was calculated based on reported monthly income and they were then asked to confirm if it corresponded to their actual earnings. As for benefits, participants were asked to specify which amount they received for each type of benefit (instead of simply indicating a global amount, as in Study 2). Personal monthly income and benefits were used both for the calculation of objective SES (z-transformed and combined with education, $\alpha=0.19$; correlation between total income and education $=.11$ ) and to evaluate our participants' actual position in the British income distribution.

Subjective SES was again calculated by combining the three items from Griskevicius et al. $(2013)(\alpha=0.65$, inter-item correlation $=0.38)$ and participants' response to the MacArthur Scale. We used a slightly modified version of the MacArthur scale focusing on income rather than education and jobs: "Think of this scale as representing where people stand in the United Kingdom. At the top of the scale (10) are the people who are the best off in terms of overall income. At the bottom (1) are the people who are the worst off in terms of overall income. Where would you place yourself on this scale?". The correlation between Griskevicius et al.'s (2013) scale and the MacArthur Scale was similar to that found in Study $2(\mathrm{r}=0.55, p<.001)$. The detailed list of all socioeconomic variables is available in the OSF-folder for this study (https://osf.io/yztx9/).

\section{- Treatment: information shock}

For all participants, the sum of their reported income and taxable benefits was calculated to determine which decile they belonged to. These calculations were 
based on statistics from the British government's Personal Income statistics release, which provides percentiles of total annual income (comprising taxable benefits).

This decile was compared to their answer to the MacArthur scale, so as to estimate the extent to which participants had a biased perception of where in the income distribution they were located. We define the bias of a participant as the difference between their perceived and actual income decile. Participants who underestimated their relative income by 1 decile point or more were categorized as having a negative bias. Participants who overestimated their relative income by 1 decile point or more were categorized as having a positive bias. The remaining participants were defined as having no bias. For those who show no bias or a positive bias, the questionnaire came to an end, and only those with a negative bias were randomly assigned to the treatment or control condition. Participants in the treatment condition were presented with a correction of the previous answer they gave, thus receiving a subjective positive income shock, based on their reported income and taxable benefits.

\section{- Pro-environmental behaviour}

In Study 2, measuring pro-environmental behaviour with a donation question did not yield significant results. In this third study, we used a modified version of the question to improve its validity. Participants were told that we were going to give $10 p$ to a research foundation for every person that participates in our study, and that they could choose the two causes they preferred. We presented them with the following options: research for climate change mitigation, medical cancer research, research in education sciences, space exploration research, research on Alzheimer disease, or research in economic policies. We only included causes that are relevant for British participants and we presented the various options in general terms (e.g., climate change mitigation as opposed to reforestation programmes), in an effort to reduce noise. Answers were transformed into a binary pro-environmental variable (presence of the cause "Research for climate change mitigation" among the two choices $=1$, absence $=0$ ). Based on participants' choices, we effectively donated the corresponding amount to relevant organizations afterwards.

\subsection{Statistical analyses}

We used an independent t-test to test our main hypothesis that mean discount rate is different between the control and the treatment groups. The exploratory hypotheses were then tested with regression analyses. To test our hypothesis about the moderating effect of the magnitude of the negative bias, the following preregistered model was used:

$$
\text { DiscountRate }=\beta_{10}+\beta_{11} \text { Treatment }+\beta_{12} \text { Bias }+\beta_{13} \text { Treatment } * \text { Bias }+\epsilon
$$

Where Treatment corresponds to a binary variable indicating whether a participant is in the control group or the treatment group, Bias is a continuous variable referring to the difference between perceived and actual income decile, and Discount Rate corresponds to the area under the curve calculated with the discounting task. In addition, following our mediation model we expected that a treatment impacting 
time preferences would have a downstream effect on pro-environmentalism. Therefore we also predicted a moderated effect of the treatment on pro-environmental attitudes and behaviour:

Environmentalism $=\beta_{14}+\beta_{15}$ Treatment $+\beta_{16}$ Bias $+\beta_{17}$ Treatment $*$ Bias $+\epsilon$

Finally, since we aimed to replicate our previous findings, we conducted the same cross-sectional analyses as in Study 2. All variables were calculated as in Study 2 and the regression models had the same specifications:

$$
\begin{aligned}
& \text { Environmentalism }=\beta_{10}+\beta_{11} S E S+\epsilon \\
& \text { DiscountRate }=\beta_{12}+\beta_{13} S E S+\epsilon \\
& \text { Environmentalism }=\beta_{14}+\beta_{15} S E S+\beta_{16} \text { DiscountRate }+\epsilon
\end{aligned}
$$

The significance of the indirect pathway was again tested with bootstrapping, using R mediation package (Tingley et al., 2014).

\subsection{Results}

Descriptive statistics for key variables are reported in Table 5, while Table 6 provides the regression estimates for the exploratory models. Figures 1 and 2 in the Supplementary Materials display the distribution of bias respectively in the sample of British candidates who were screened for eligibility to the study, and in the final sample of negatively biased participants who were retained $(\mathrm{N}=855)$. As opposed to Karadja et al.'s (2015) study in which bias distribution was substantially skewed to the right (indicating that a majority of their Swedish respondents underestimated their position), the distribution in Figure 1 is normal. Although this sample is not representative, this suggests that Britons might not underestimate their relative wealth as much as the Swedes. Participants were not homogeneously distributed across the various levels of bias, with a majority displaying a bias lower than 2 (i.e. underestimating their relative income by less than 2 deciles). Therefore, we pooled participants in broader categories: participants who underestimated their relative income by 1 decile were classified as "very low bias", those who underestimated their relative income by 2 were classified as "low bias", those who underestimated their relative income by 3 were classified as "medium bias" and those above 4 were classified as "high bias".

\section{Main and exploratory analyses}

Contrary to our hypotheses, the information shock had no impact on temporal discount rates, which were not different in the control group and the treatment group $(t=-0.15938, p=.87)$; and there was no moderated effect of the treatment on temporal discounting depending on the magnitude of the bias (see Table 6).

However, additional analyses revealed that the impact of the treatment on proenvironmental behaviour was affected by the magnitude of the bias: although we observed no main effect of the treatment on pro-environmental behaviour in the full sample $(\beta=0.02, p=.569)$, participants in the medium bias and high bias groups responded more to the treatment than participants in the very low bias group (medium bias: $\beta=0.21, p=.026$; high bias: $\beta=0.21, p=.049$, see Table 6). Similar results were found for pro-environmental attitudes: participants 
with a high bias responded more to the treatment than those with a very low bias $(\beta=0.42, p=.047$, see Table 6$)$. These interactive effects are represented in Figure 2 .

Table 5: Descriptive statistics

\begin{tabular}{lccccc}
\hline \hline Statistic & $\mathrm{N}$ & Mean & St. Dev. & Min & Max \\
\hline Education score & 855 & 4.1 & 0.9 & 1 & 5 \\
Total income (including benefits) & 855 & 2,736 & 1,258 & 1,200 & 12,000 \\
Griskevicius items & 855 & 12.7 & 3.3 & 3 & 21 \\
MacArthur Scale & 855 & 5.2 & 1.5 & 1 & 9 \\
AUC (temporal discounting) & 855 & 20,501 & 12,934 & 709 & 49,276 \\
Conservation score & 855 & 5.2 & 1 & 1 & 7 \\
Activism score & 855 & 4.2 & 1.2 & 1 & 7 \\
Pro-environmental behaviour & 855 & 0.4 & 0.5 & 0 & 1 \\
Treatment & 855 & 0.5 & 0.5 & 0 & 1 \\
Bias & 855 & -2.2 & 1.2 & -7 & -1 \\
\hline
\end{tabular}

Note: Activism score and Conservation score refer to Milfont and Duckitt's (2010) scales from the Environmental Attitudes Inventory, which were used to calculate participants' proenvironmental attitudes. See detailed definition of each variable in subsections 3.1.2 and 4.1.3.

Figure 2: Interactive effects of the treatment and the magnitude of the bias on proenvironmental attitudes and behaviour

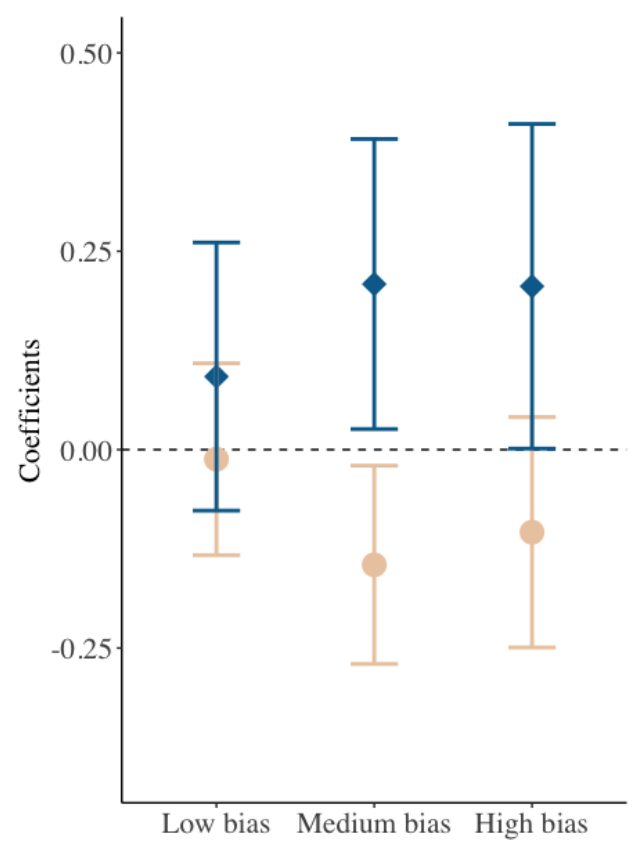

(a) Pro-environmental behaviour

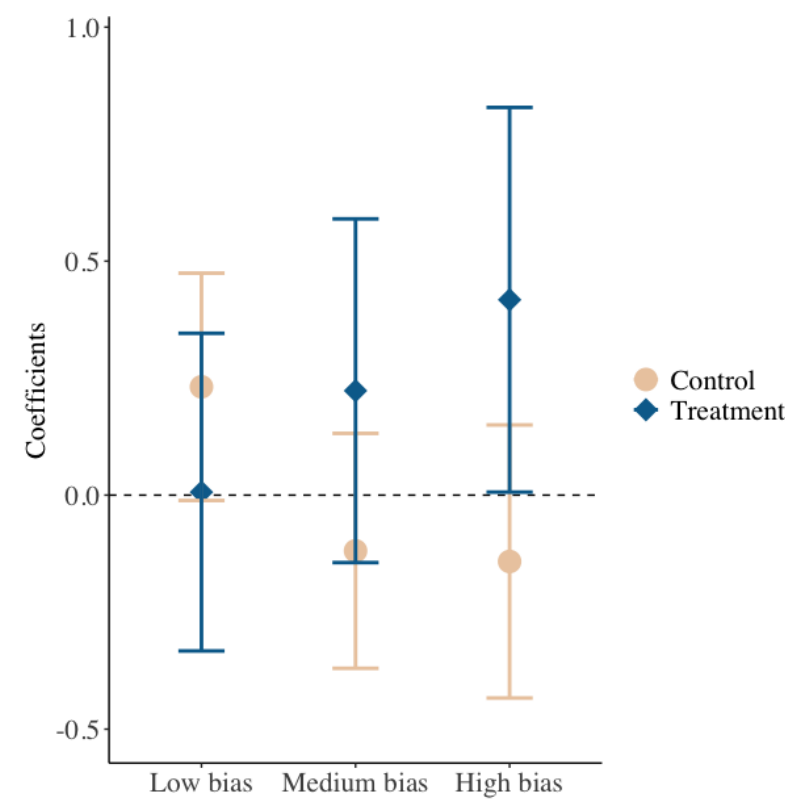

(b) Pro-environmental attitudes

Note: These graphs are visual depictions of the interactions between the treatment (information shock concerning relative income) and the magnitude of the bias. The data points represent the coefficients of models 4 and 6 from Table 6 and error bars represent $95 \%$ confidence intervals. The omitted category is very low bias. 
Table 6: Main effect and moderated effect of the treatment on temporal discounting and environmentalism

\begin{tabular}{|c|c|c|c|c|c|c|}
\hline & \multicolumn{6}{|c|}{ Dependent variable: } \\
\hline & \multicolumn{2}{|c|}{ Temporal discounting } & \multicolumn{2}{|c|}{ Pro-environmental attitudes } & \multicolumn{2}{|c|}{ Pro-environmental behaviour } \\
\hline & (1) & (2) & (3) & (4) & (5) & (6) \\
\hline Treatment & $\begin{array}{c}0.01 \\
(-0.13,0.14)\end{array}$ & $\begin{array}{c}-0.02 \\
(-0.25,0.21)\end{array}$ & $\begin{array}{c}-0.10 \\
(-0.24,0.03)\end{array}$ & $\begin{array}{c}-0.22 \dagger \\
(-0.45,0.01)\end{array}$ & $\begin{array}{c}0.02 \\
(-0.05,0.09)\end{array}$ & $\begin{array}{c}-0.08 \\
(-0.20,0.03)\end{array}$ \\
\hline Low Bias & $\begin{array}{c}0.05 \\
(-0.12,0.22)\end{array}$ & $\begin{array}{c}-0.10 \\
(-0.35,0.14)\end{array}$ & $\begin{array}{c}0.22^{*} \\
(0.05,0.39)\end{array}$ & $\begin{array}{c}0.23 \dagger \\
(-0.01,0.47)\end{array}$ & $\begin{array}{c}0.03 \\
(-0.06,0.11)\end{array}$ & $\begin{array}{c}-0.01 \\
(-0.13,0.11)\end{array}$ \\
\hline Medium Bias & $\begin{array}{c}-0.04 \\
(-0.22,0.15)\end{array}$ & $\begin{array}{c}0.05 \\
(-0.20,0.30)\end{array}$ & $\begin{array}{c}-0.02 \\
(-0.20,0.17)\end{array}$ & $\begin{array}{c}-0.12 \\
(-0.37,0.13)\end{array}$ & $\begin{array}{c}-0.05 \\
(-0.14,0.04)\end{array}$ & $\begin{array}{c}-0.15^{*} \\
(-0.27,-0.02)\end{array}$ \\
\hline High Bias & $\begin{array}{c}-0.12 \\
(-0.33,0.08)\end{array}$ & $\begin{array}{c}-0.08 \\
(-0.37,0.22)\end{array}$ & $\begin{array}{c}0.07 \\
(-0.14,0.28)\end{array}$ & $\begin{array}{c}-0.14 \\
(-0.43,0.15)\end{array}$ & $\begin{array}{c}-0.003 \\
(-0.11,0.10)\end{array}$ & $\begin{array}{c}-0.10 \\
(-0.25,0.04)\end{array}$ \\
\hline Treatment x Low Bias & & $\begin{array}{c}0.28 \\
(-0.06,0.62)\end{array}$ & & $\begin{array}{c}0.01 \\
(-0.33,0.35)\end{array}$ & & $\begin{array}{c}0.09 \\
(-0.08,0.26)\end{array}$ \\
\hline Treatment x Medium Bias & & $\begin{array}{c}-0.18 \\
(-0.55,0.19)\end{array}$ & & $\begin{array}{c}0.22 \\
(-0.14,0.59)\end{array}$ & & $\begin{array}{c}0.21^{*} \\
(0.03,0.39)\end{array}$ \\
\hline Treatment x High Bias & & $\begin{array}{c}-0.09 \\
(-0.50,0.33)\end{array}$ & & $\begin{array}{c}0.42^{*} \\
(0.01,0.83)\end{array}$ & & $\begin{array}{c}0.21^{*} \\
(0.001,0.41)\end{array}$ \\
\hline Intercept & $\begin{array}{c}0.01 \\
(-0.12,0.14)\end{array}$ & $\begin{array}{c}0.02 \\
(-0.13,0.18)\end{array}$ & $\begin{array}{c}-0.02 \\
(-0.15,0.11)\end{array}$ & $\begin{array}{c}0.03 \\
(-0.12,0.19)\end{array}$ & $\begin{array}{c}0.43^{* * *} \\
(0.36,0.49)\end{array}$ & $\begin{array}{c}0.47^{* * *} \\
(0.40,0.55)\end{array}$ \\
\hline Observations & 855 & 855 & 855 & 855 & 855 & 855 \\
\hline & 0.003 & 0.01 & 0.01 & 0.02 & 0.003 & 0.01 \\
\hline Adjusted $\mathrm{R}^{2}$ & -0.001 & 0.003 & 0.01 & 0.01 & -0.001 & 0.003 \\
\hline RSE & $1.001(\mathrm{df}=850)$ & $0.999(\mathrm{df}=847)$ & $0.996(\mathrm{df}=850)$ & $0.995(\mathrm{df}=847)$ & $0.496(\mathrm{df}=850)$ & $0.495(\mathrm{df}=847)$ \\
\hline F Statistic & $0.69(\mathrm{df}=4 ; 850)$ & $1.31(\mathrm{df}=7 ; 847)$ & $2.52^{*}(\mathrm{df}=4 ; 850)$ & $2.19^{*}(\mathrm{df}=7 ; 847)$ & $0.74(\mathrm{df}=4 ; 850)$ & $1.38(\mathrm{df}=7 ; 847)$ \\
\hline
\end{tabular}

Note: OLS regressions. Confidence intervals in parentheses. $\dagger \mathrm{p}<0.1 ;{ }^{*} \mathrm{p}<0.05 ;{ }^{* *} \mathrm{p}<0.01 ;{ }^{* * *} \mathrm{p}<0.001$. This table estimates the heterogeneous effect of the treatment (subjective positive income shock) depending on the magnitude of participants' bias. The four categories do not have the same number of observations. The omitted category is very low bias.

\section{Replication of the correlational mediation model}

As was pre-registered, additional mediation analyses were conducted to replicate the correlational mediation model found in the previous study. Following Baron and Kenny's (1986) approach, we replicated the overall patterns found in the previous study (we do not include the detail of these analyses here, but they are available in Tables 6 and 7 in the Supplementary Materials). The only discrepancy with Study 2 was that subjective SES was not significantly associated with pro-environmental attitudes $(\beta=0.01, p=.80)$.

The analyses based on bootstrapping also yielded very similar results to those from Study 2: we observed again a positive mediated effect of objective SES on pro-environmental attitudes via temporal discounting $(\beta=0.012, p=.01)$, as well as a direct effect $(\beta=0.085, p=.03$, see Table 9 in the Supplementary Materials). As in Study 2, we found no significant direct or mediated effect of objective SES on pro-environmental behaviour. The bootstrapping procedure also indicated that the relationship between subjective SES and pro-environmental attitudes was significantly mediated by temporal discounting $(\beta=0.026, p=.01)$, while there was no direct effect $(\beta=-0.014, p=.77)$. One difference with Study 2 was that this time we found a significant mediated association between subjective SES and pro-environmental behaviour $(\beta=0.010, p=.04)$. 
The fact that, in contrast to Study 2, the mediated association between subjective SES and pro-environmental behaviour became significant in Study 3 can be attributed to changes in the donation question, that were aimed at improving its validity. This seems to bring additional support for our mediation model. However, it should be noted that this can also be attributed to differences in the samples. Study 3 is not a perfect replication of the previous one, as we only retained participants who had a negative perception bias concerning their position in the income distribution. This affected the composition of the sample: in particular, participants in Study 3 had in average higher incomes, educational levels and AUCs than in Study 2 (see Tables 2 and 5).

Finally, we also examined the separate effects of total income and education levels. As in the previous study, we found that education had a slightly stronger mediated effect $(\beta=0.010, p=.03)$ than total income $(\beta=0.006, p=.04)$, and that total income had no direct effect on pro-environmental attitudes $(\beta=-0.010$, $p=.77$, see Table ?? in the Supplementary Materials).

\subsection{Discussion}

Prior research has shown that time preferences can shift in response to an experimental shock, for example by exposing participants to positive or negative income shocks in economic games (Haushofer et al., 2013), or by using narratives about a sudden change to one's future income (an experimental treatment also known as episodic future thinking, see Bickel et al., 2016; Liu et al., 2013; Mellis et al., 2018; Sze et al., 2017). In our experiment however, providing participants with positive information about their relative income did not have an effect on temporal discounting. But this treatment had positive interactive effects on environmentalism, such that participants who were the most biased about their relative income responded to the treatment with more positive pro-environmental behaviour and attitudes. The fact that the effects are not mediated by temporal discounting was not anticipated and our data do not allow us to identify the causal channel of change.

One possibility is that, rather than activating considerations about the future, our experimental treatment activated considerations about fairness, which may have had a downstream effect on participants' pro-environmental behaviour. There is indeed a wealth of studies showing that correcting false beliefs about socioeconomic position heightens concerns about inequalities for people who learn that they are poorer than they thought relative to others, while those who learn they are relatively richer put less priority on fairness and redistribution (Cruces et al., 2013; Hvidberg et al., 2020; Karadja et al., 2015; Mijs and Hoy, 2021; Nair, 2018). On the other hand, there is evidence that the importance that people place on fairness affects their willingness to protect the environment. Studies show that people are reluctant to support environmental public policies such as the carbon tax mainly because they believe it to be unfair (Douenne and Fabre, 2020; Sommer et al., 2020). Another example of the importance of fairness concerns can be found in an annual French survey about social representations of climate change: when respondents are asked on what condition they would be willing to make significant lifestyle changes to reduce their emissions, their priority since 2015 has systematically been that efforts be shared fairly among all members of society (ADEME, 2020). In our study, participants in the treatment group might have been less concerned by fairness 
and more willing to accept environmental measures and sacrifices that are generally deemed unfair. But this interpretation remains speculatory since we did not measure participants' attitudes about fairness.

In addition, this last study globally replicated the correlational results of the previous study: as in Study 2, we found that the association between SES and proenvironmental attitudes was mediated by temporal discounting. We also observed a mediated effect of subjective SES on pro-environmental behaviour. Thus, Study 3 brings additional support for our mediation hypothesis, although further research with experimental data is needed to ascertain the robustness of this causal model.

\section{General discussion}

The present investigation is related to a vast literature on the relationships between SES and pro-environmental attitudes and behaviour. Relying on psychological theories of poverty, we aimed to gain a better understanding of the mechanisms underlying this relationship. We hypothesized that temporal discounting is one of the factors accounting for socioeconomic differences in pro-environmentalism. Our three studies provide support for this mediation hypothesis. Our results across all studies are compatible with the idea that the correlation between SES and environmental attitudes is partially mediated by time preferences. In Study 3, we found that providing participants with positive information about their relative income had a heterogeneous effect on pro-environmental attitudes and behaviour, but contrary to our hypothesis, the treatment had no impact on temporal discounting.

This research makes several contributions to the literature. First, our studies are the first to test the hypothesis that time preferences mediate the effect of SES on environmentalism. Social scientists have long been interested in the influence of SES on environmental attitudes (Buttel and Flinn, 1978; Diamantopoulos et al., 2003; Harry et al., 1969), but few studies have explored the psychological mechanisms that underpin this relationship (Eom et al., 2018).

Second, surveys have often focused on objective markers of SES such as profession, income and education, rather than using self-report scales measuring individuals' subjective experience. Our studies rely on measures of SES that include both subjective and objective indicators. This allowed us to detect that subjective measures are correlated with pro-environmental attitudes in the same way as objective markers of SES. However, subjective measures appear to have a more consistent effect than income. Results from Study 1 for instance, indicate that education and subjective SES are associated with several types of pro-environmental attitudes, whereas income was correlated positively with pro-environmentalism but not with willingness to increase green taxes and public spending. This is coherent with previous research showing that education is a stronger predictor of pro-environmentalism than income, which can have opposite effects on different types of pro-environmental attitudes (Blankenberg and Alhusen, 2018; Lo, 2016; Marquart-Pyatt, 2012; Pearson et al., 2017). Thus, although the relationship between socio-demographic factors and environmental attitudes has been much studied, Study 1 contributes to the literature on this topic by using more comprehensive measures of SES, while relying on a very large French sample representing a broad range of the population's diversity.

Third, by highlighting the role of time preferences as a potential mediator of the relationship between SES and pro-environmentalism, studies 2 and 3 bring together 
two streams of research about pro-environmental attitudes and behaviours that have rarely converged into a common approach: one which focuses on socio-demographic determinants and the other on social psychological determinants (Dietz et al., 1998).

This potential role of time preferences may be of particular interest for policymakers. Having a better understanding of the factors that drive pro-environmental attitudes and behaviour is indeed crucial for decision-makers who seek to implement environmental policies. A growing literature in psychology has started to address these issues (see Nielsen et al., 2020). For instance, in a recent article, Eom et al. (2018) examined the influence of social class, beliefs in climate change and sense of control on pro-environmental action. Their studies suggest two types of strategies for promoting green behaviour: efforts should focus on changing the beliefs of high SES individuals who do not believe in climate change, and on giving a greater sense of control to low SES individuals who do believe in climate change.

Our mediation model could suggest a similar two-way strategy to promote proenvironmental behaviour, depending on SES: since higher SES individuals tend to be more future-oriented, communication focused on the future costs of unmitigated climate change or biodiversity loss might be more convincing for them than for lower SES individuals. For the latter, highlighting the proximal consequences of environmental issues and bringing them psychologically closer could be more efficient. However, despite this being a frequent suggestion to increase individuals' willingness to act for the environment, empirical research testing this proximizing approach has not consistently revealed the expected positive effects on climate-friendly behaviour so far (Brügger et al., 2015; Spence et al., 2012). Mixed results suggest that the effects of proximizing are more complex than is commonly assumed. Further research on how it affects the willingness to act of different segments of the population is needed before large-scale interventions relying on proximizing are implemented.

The experimental results of Study 3 also suggest other directions for future research on the relationship between SES, temporal discounting and environmentalism. Since providing information about relative income does not seem to impact discount rates, future research aiming to study the causal impact of SES on time preferences and environmentalism should rather focus on narratives and informational treatments which highlight changes in absolute levels of income. For this purpose, the use of episodic future thinking about income shocks, which consists in projecting the self into the future to pre-experience a positive or negative income shock, has proven its efficacy to shift temporal discounting (Bickel et al., 2016; Sze et al., 2017). Similarly, some studies have shown that engaging in episodic future thinking about climate change-related risks and climate change mitigation leads to acting pro-environmentally (Ho et al., 2020; Lee et al., 2020). Future research could assess whether episodic future thinking about income shocks has a similar effect on pro-environmental behaviour, and whether this effect is partially mediated by temporal discounting. Another possibility would be to test the impact of influencing beliefs about relative education level, rather than income. Since we found that the mediated effect of education on pro-environmentalism was somewhat stronger than the mediated effect of income, this might be a more effective experimental treatment than providing information about income.

In addition, the interactive effects of the subjective positive income shock on proenvironmental attitudes and behaviour evidenced in Study 3 suggest new avenues for research and interventions targeting pro-environmental behaviour. Additional surveys are needed to understand the psychological mechanisms behind this ob- 
served treatment effect. Since previous research has repeatedly shown that such a treatment has an effect on attitudes about fairness and redistribution, future studies could explore how socioeconomic differences in pro-environmentalism might be related to attitudes about fairness and redistribution.

Future research should also examine the extent to which the results generalize to other countries. Our hypotheses are not country-specific because several multicountry studies have found systematic patterns of relationship between income, proenvironmental attitudes and behaviours on the one hand (Lo, 2016; Marquart-Pyatt, 2012; Pisano and Lubell, 2017) and between temporal discounting and income on the other (Wang et al., 2016). However, it will be important to validate this model empirically. Even within the same country, there could also be variations according to individuals' ethnicity. Including participants' ethnicity as a control variable may be especially relevant, since it is sometimes correlated with SES.

There are several limitations to this research, the first being the absence of experimental evidence for our partial mediation model. Thus, different theories about how time preferences relate to pro-environmentalism and SES should be considered. Another possible limitation of our last two studies concerns the measurement of proenvironmental behaviour: unlike environmental attitudes, there is no standardized measure of pro-environmental behaviour for online studies (Lange and Dewitte, 2019). While Study 2 appears to validate our mediation model with respect to environmental attitudes, no significant mediated relationship was found for behaviour. It remains unclear whether we did not find the same results because of an essential difference between pro-environmental behaviour and attitudes, or because of a lack of validity of our behavioural measure. In Study 2, pro-environmental behaviour measured by a donation to reforestation programmes showed only a low to medium correlation with a validated pro-environmental attitudes scale (Milfont and Duckitt, 2010). Many studies have evidenced a value-action gap in the environmental domain (see Kollmuss and Agyeman, 2002), therefore this discrepancy between attitudes and behaviour does not come as a surprise. However, the magnitude of this discrepancy is surprising, as the correlation is still lower than could be expected. Other considerations related to the alternative donation choices offered to participants may also call into question the validity of the behavioural measure that we used. In Study 3 , a transformation of the variable to measure donation to a more global environmental action, and the use of different alternative choices led to a higher correlation with attitudes, which suggests a higher validity of the measure. In addition, there was a mediated effect of subjective SES on pro-environmental behaviour which was similar to that observed for pro-environmental attitudes. But these variations from Study 2 to Study 3 could also be attributed to differences in the samples. Further research could be conducted with other measures of pro-environmental behaviour to test the robustness of our mediation model with respect to behaviour.

Another limitation might be that the individual discount rates inferred from a monetary discounting task cannot be considered as pure measures of time preferences: responses can be influenced by participants' budgetary constraints and the interest rates of the markets to which they have access (see Frederick et al., 2002; Wang et al., 2016). There has been considerable discussion in the literature as to whether observed socioeconomic differences in temporal discounting actually reflect differences in preferences, or whether they may instead reflect actual or perceived liquidity constraints in conditions of poverty (Haushofer et al., 2013). Thus, it would be interesting to see whether our results replicate using non-monetary rewards in 
the discounting task, such as environmental gains. However, it is worth noting that according to previous research, individuals discount environmental outcomes in a similar way to monetary outcomes (Hardisty and Weber, 2009).

Finally, it should be emphasized that temporal discounting seems to explain only a small part of the association between SES and pro-environmental attitudes: correlational results from Studies 2 and 3 highlight very small effect sizes, and the mediated effect of objective SES was significantly weaker than the direct effect. Other social psychological factors, such as sense of control, may be stronger mediators of the relationship between SES and pro-environmentalism. Studies which evaluate the relative contribution of different factors would thus be welcome. These small effect sizes also suggest that the association between SES and pro-environmentalism is complex and may depend on behaviours or contexts. In addition, there are other factors that we did not incorporate in our mediation model and that are known to moderate the relationship between SES and pro-environmentalism, such as political orientation and climate change beliefs (see Ballew et al., 2020; Ehret et al., 2017; Eom et al., 2018).

Despite its limitations, the present research contributes to a scarce literature that examines the psychological mechanisms underlying the relationship between socio-demographic variables and pro-environmental attitudes and behaviour. Our three studies give weight to the hypothesis that people's preference for the future is a partial mediator of this relationship. Study 3 also shows that information about relative SES impacts pro-environmentalism via other paths. Since having a fine-grain understanding of the antecedents of pro-environmental behaviour can be consequential from an environmental policy perspective, it would be fruitful to continue exploring these lines of research.

\section{Acknowledgements}

We thank Mathilde Mus for her help with the literature review and the preparation of the third study.

\section{Conflicts of interest}

None.

\section{Funding}

This research was supported by the Agence Nationale de la Recherche (EUR FrontCog ANR-17-EURE-0017), the Institut d'Etudes Cognitives (ANR-10-IDEX0001-02 FrontCog) and the Fondation pour les sciences sociales. 


\section{References}

Ackermann, K. A. et al. (2014). "Save the Planet for Humans' Sake: The Relation between Social and Environmental Value Orientations". In: SSRN Electronic Journal. DOI: 10.2139/ssrn. 2455990.

ADEME (2020). "Représentations sociales du changement climatique : 21ème vague" par Opinior URL: https : / / librairie . ademe . fr / cadic / 4891 / barometre representations-sociales-cc-vague21-enquete-2020.pdf.

Adler, N. E., E. S. Epel, G. Castellazzo, and J. R. Ickovics (2000). "Relationship of subjective and objective social status with psychological and physiological functioning: Preliminary data in healthy, White women." In: Health Psychology 19.6, pp. 586-592. DOI: 10.1037/0278-6133.19.6. 586.

Aguinis, H., J. R. Edwards, and K. J. Bradley (2016). "Improving Our Understanding of Moderation and Mediation in Strategic Management Research". In: Organizational Research Methods 20.4, pp. 665-685. DOI: 10. $1177 / 1094428115627498$.

Ballew, M. T. et al. (2020). "Does socioeconomic status moderate the political divide on climate change? The roles of education, income, and individualism". In: Global Environmental Change 60, p. 102024.

Baron, R. M. and D. A. Kenny (1986). "The moderator-mediator variable distinction in social psychological research: Conceptual, strategic, and statistical considerations." In: Journal of personality and social psychology 51.6, p. 1173.

Bickel, W. K. et al. (2016). "Stuck in Time: Negative Income Shock Constricts the Temporal Window of Valuation Spanning the Future and the Past". In: PloS one 11.9. Ed. by P. G. Roma, e0163051. DoI: 10.1371/journal. pone.0163051.

Bickel, W. K. et al. (2014). "A competing neurobehavioral decision systems model of SES-related health and behavioral disparities". In: Preventive medicine 68, pp. 37-43.

Blankenberg, A.-K. and H. Alhusen (2018). "On the determinants of pro-environmental behavior - a guide for further investigations". In: CEGE Discussion Paper Number 350.

Brügger, A. et al. (2015). "Psychological responses to the proximity of climate change". In: Nature climate change 5.12, pp. 1031-1037.

Buttel, F. H. and W. L. Flinn (1978). "Social class and mass environmental beliefs: A reconsideration". In: Environment and Behavior 10.3, pp. 433450.

Card, D., A. Mas, E. Moretti, and E. Saez (2012). "Inequality at work: The effect of peer salaries on job satisfaction". In: American Economic Review 102.6, pp. 2981-3003.

Cassar, A., A. Healy, and C. Von Kessler (2017). "Trust, risk, and time preferences after a natural disaster: experimental evidence from Thailand". In: World Development 94, pp. 90-105. 
Cené, C. W. et al. (2016). "Associations between subjective social status and physical and mental health functioning among patients with hypertension". In: Journal of health psychology 21.11, pp. 2624-2635.

Clements, J. M., A. M. McCright, T. Dietz, and S. T. Marquart-Pyatt (2015). "A behavioural measure of environmental decision-making for social surveys". In: Environmental Sociology 1.1, pp. 27-37.

Coller, M. and M. B. Williams (1999). "Eliciting individual discount rates". In: Experimental Economics 2.2, pp. 107-127.

Cruces, G., R. Perez-Truglia, and M. Tetaz (2013). "Biased perceptions of income distribution and preferences for redistribution: Evidence from a survey experiment". In: Journal of Public Economics 98, pp. 100-112.

Delgado, M. S., J. L. Harriger, and N. Khanna (2015). "The value of environmental status signaling". In: Ecological Economics 111, pp. 1-11.

Di Falco, S., P. Berck, M. Bezabih, and G. Köhlin (2019). "Rain and impatience: Evidence from rural Ethiopia". In: Journal of Economic Behavior \& Organization 160, pp. 40-51.

Diamantopoulos, A., B. B. Schlegelmilch, R. R. Sinkovics, and G. M. Bohlen (2003). "Can socio-demographics still play a role in profiling green consumers? A review of the evidence and an empirical investigation". In: Journal of Business research 56.6, pp. 465-480.

Dietz, T., P. C. Stern, and G. A. Guagnano (1998). "Social structural and social psychological bases of environmental concern". In: Environment and behavior 30.4, pp. 450-471.

Douenne, T. and A. Fabre (2020). "Yellow vests, carbon tax aversion, and biased beliefs". In: HAL.

Eby, B., A. R. Carrico, and H. B. Truelove (2019). "The influence of environmental identity labeling on the uptake of pro-environmental behaviors". In: Climatic Change 155.4, pp. 563-580.

Ehret, P. J., A. C. Sparks, and D. K. Sherman (2017). "Support for environmental protection: an integration of ideological-consistency and information-deficit models". In: Environmental Politics 26.2, pp. 253-277.

Enzler, H. B., A. Diekmann, and R. Meyer (2014). "Subjective discount rates in the general population and their predictive power for energy saving behavior". In: Energy Policy 65, pp. 524-540. DOI: $10.1016 / \mathrm{j}$. enpol . 2013.10.049.

Eom, K., H. S. Kim, and D. K. Sherman (2018). "Social class, control, and action: Socioeconomic status differences in antecedents of support for proenvironmental action". In: Journal of Experimental Social Psychology 77, pp. 60-75. DOI: $10.1016 / j \cdot$ jesp. 2018.03.009.

Fehr, D., J. Mollerstrom, and R. Perez-Truglia (2019). "Your Place in the World: The Demand for National and Global Redistribution". In: National Bureau of Economic Research.

Forsé, M. and M. Parodi (2015). "Les Français et la justice fiscale". In: Revue de l'OFCE 1, pp. 97-132.

Franzen, A. and R. Meyer (2009). "Environmental Attitudes in Cross-National Perspective: A Multilevel Analysis of the ISSP 1993 and 2000". In: 
European Sociological Review 26.2, pp. 219-234. DOI: 10 . 1093 / esr / jcp018.

Frederick, S., G. Loewenstein, and T. O'donoghue (2002). "Time discounting and time preference: A critical review". In: Journal of economic literature 40.2, pp. 351-401.

Frye, C. C. et al. (2016). "Measuring Delay Discounting in Humans Using an Adjusting Amount Task". In: Journal of Visualized Experiments 107. DOI: $10.3791 / 53584$.

Ghaed, S. G. and L. C. Gallo (2007). "Subjective social status, objective socioeconomic status, and cardiovascular risk in women." In: Health Psychology 26.6 , p. 668.

Green, L., A. F. Fry, and J. Myerson (1994). "Discounting of delayed rewards: A life-span comparison". In: Psychological science 5.1, pp. 33-36.

Green, L. et al. (1996). "Temporal discounting in choice between delayed rewards: the role of age and income". In: Psychology and aging 11.1, p. 79.

Griskevicius, V. et al. (2013). "When the economy falters, do people spend or save? Responses to resource scarcity depend on childhood environments". In: Psychological science 24.2, pp. 197-205.

Guerin, D., J. Crete, and J. Mercier (2001). "A multilevel analysis of the determinants of recycling behavior in the European countries". In: Social science research 30.2, pp. 195-218.

Guillou, L., A. Grandin, and C. Chevallier (2021). "Temporal discounting mediates the relationship between socio-economic status and social trust". In: Royal Society Open Science 8.6, p. 202104.

Haisley, E., R. Mostafa, and G. Loewenstein (2008). "Subjective relative income and lottery ticket purchases". In: Journal of Behavioral Decision Making 21.3, pp. 283-295. DOI: 10 . 1002/bdm. 588.

Haller, M. and M. Hadler (2008). "Dispositions to Act in Favor of the Environment: Fatalism and Readiness to Make Sacrifices in a Cross-National Perspective". In: Sociological Forum 23.2, pp. 281-311.

Hardisty, D. J. and E. U. Weber (2009). "Discounting future green: money versus the environment." In: Journal of Experimental Psychology: General 138.3 , p. 329.

Harrison, G. W., M. I. Lau, and M. B. Williams (2002). "Estimating Individual Discount Rates in Denmark: A Field Experiment". In: The American Economic Review 92.5, pp. 1606-1617.

Harry, J., R. Gale, and J. Hendee (1969). "Conservation: An upper-middle class social movement". In: Journal of Leisure Research 1.3, pp. 246-254.

Haushofer, J., D. Schunk, and E. Fehr (2013). "Negative income shocks increase discount rates". In: University of Zurich Working Paper.

Hausman, J. A. (1979). "Individual discount rates and the purchase and utilization of energy-using durables". In: The Bell Journal of Economics, pp. 33-54. 
Hines, J. M., H. R. Hungerford, and A. N. Tomera (1987). "Analysis and synthesis of research on responsible environmental behavior: A meta-analysis". In: The Journal of environmental education 18.2, pp. 1-8.

Ho, L.-C. et al. (2020). "Envisaging Mitigation Action Can Induce Lower Discounting toward Future Environmental Gains and Promote ProEnvironmental Behavior". In: Sustainability 12.21, p. 9289.

Holmbeck, G. N. (2002). "Post-hoc probing of significant moderational and mediational effects in studies of pediatric populations". In: Journal of pediatric psychology 27.1, pp. 87-96.

Hvidberg, K. B., C. T. Kreiner, and S. Stantcheva (2020). "Social Position and Fairness Views". In: NBER Working Paper w28099.

Johnson, M. W. and W. K. Bickel (2002). "Within-subject comparison of real and hypothetical money rewards in delay discounting". In: Journal of the experimental analysis of behavior 77.2 , pp. 129-146.

Karadja, M., J. Mollerstrom, and D. Seim (2015). "Richer (and Holier) than Thou? The Effect of Relative Income Improvements on Demand for Redistribution". In: SSRN Electronic Journal. DOI: 10.2139/ssrn. 2565138.

Kennedy, E. H., S. Baumann, and J. Johnston (2018). "Eating for Taste and Eating for Change: Ethical Consumption as a High-Status Practice". In: Social Forces. DOI: 10.1093/sf/soy113.

Kennedy, E. H. and J. E. Givens (2019). "Eco-habitus or Ecopowerlessness? Examining Environmental Concern across Social Class". In: Sociological Perspectives, p. 073112141983696. DOI: 10 . 1177 / 0731121419836966.

Kirby, K. N. and N. N. Maraković (1995). "Modeling myopic decisions: Evidence for hyperbolic delay-discounting within subjects and amounts". In: Organizational Behavior and Human decision processes 64.1, pp. 22-30.

Kollmuss, A. and J. Agyeman (2002). "Mind the Gap: Why do people act environmentally and what are the barriers to pro-environmental behavior?" In: Environmental Education Research 8.3, pp. 239-260. DOI: 10.1080 / 13504620220145401.

Kortenkamp, K. V. and C. F. Moore (2006). "Time, Uncertainty, and Individual Differences in Decisions to Cooperate in Resource Dilemmas". In: Personality and Social Psychology Bulletin 32.5, pp. 603-615. DOI: 10 . $1177 / 0146167205284006$.

Kraus, M. W. and N. M. Stephens (2012). "A road map for an emerging psychology of social class". In: Social and Personality Psychology Compass 6.9, pp. 642-656.

Lange, F. and S. Dewitte (2019). "Measuring pro-environmental behavior: Review and recommendations". In: Journal of Environmental Psychology 63, pp. 92-100.

Lavergne, K. J. and L. G. Pelletier (2015). "Predicting individual differences in the choice of strategy to compensate for attitude-behaviour inconsistencies in the environmental domain". In: Journal of Environmental Psychology 44, pp. 135-148. ISSN: 02724944. DOI: 10.1016/j.jenvp.2015.10.001. 
Lawrance, E. C. (1991). "Poverty and the rate of time preference: evidence from panel data". In: Journal of Political economy 99.1, pp. 54-77.

Lee, P.-S. et al. (2020). "Using episodic future thinking to preexperience climate change increases pro-environmental behavior". In: Environment and Behavior 52.1, pp. 60-81.

Liu, L., T. Feng, J. Chen, and H. Li (2013). "The value of emotion: How does episodic prospection modulate delay discounting?" In: PloS one 8.11, e81717.

Lo, A. Y. (2016). "National income and environmental concern: Observations from 35 countries". In: Public Understanding of Science 25.7, pp. 873-890.

Maki, A. et al. (2019). "Meta-analysis of pro-environmental behaviour spillover". In: Nature Sustainability 2.4, pp. 307-315.

Mani, A., S. Mullainathan, E. Shafir, and J. Zhao (2013). "Poverty impedes cognitive function". In: Science 341.6149, pp. 976-980.

Marquart-Pyatt, S. T. (2008). "Are there similar sources of environmental concern? Comparing industrialized countries". In: Social Science Quarterly 89.5, pp. 1312-1335.

- (2012). "Contextual influences on environmental concerns cross-nationally: A multilevel investigation". In: Social Science Research 41.5, pp. 10851099. ISSN: 0049089X. DOI: 10.1016/j.ssresearch.2012.04.003.

Mellis, A. M. et al. (2018). "Less is more: Negative income shock increases immediate preference in cross commodity discounting and food demand". In: Appetite 129, pp. 155-161.

Micklewright, J. and S. V. Schnepf (2010). "How reliable are income data collected with a single question?" In: Journal of the Royal Statistical Society: Series A (Statistics in Society) 173.2, pp. 409-429.

Mijs, J. J. B. and C. Hoy (Jan. 2021). "How Information about Inequality Impacts Belief in Meritocracy: Evidence from a Randomized Survey Experiment in Australia, Indonesia and Mexico". In: Social Problems. ISSN: 0037-7791. DOI: 10.1093/socpro/spaa059.

Milfont, T. L. and J. Duckitt (2010). "The environmental attitudes inventory: A valid and reliable measure to assess the structure of environmental attitudes". In: Journal of Environmental Psychology 30.1, pp. 80-94. DOI: 10.1016/j. jenvp.2009.09.001.

Milfont, T. L., J. Wilson, and P. Diniz (2012). "Time perspective and environmental engagement: A meta-analysis". In: International Journal of Psychology 47.5, pp. 325-334.

Myerson, J., L. Green, and M. Warusawitharana (2001). "Area under the curve as a measure of discounting". In: Journal of the experimental analysis of behavior 76.2, pp. 235-243.

Nair, G. (2018). "Misperceptions of relative affluence and support for international redistribution". In: The Journal of Politics 80.3, pp. 815-830.

Nielsen, K. S. et al. (2020). "How psychology can help limit climate change." In: American Psychologist. 
Norton, M. I. and D. Ariely (2011). "Building a better America-One wealth quintile at a time". In: Perspectives on psychological science 6.1, pp. 9-12.

Norton, M. I. et al. (2014). "The not-so-common-wealth of Australia: Evidence for a cross-cultural desire for a more equal distribution of wealth". In: Analyses of Social Issues and Public Policy 14.1, pp. 339-351.

Oliphant, Z., C. M. Jaynes, and R. K. Moule Jr (2020). "Social Preferences and Environmental Behavior: A Comparison of Self-Reported and Observed Behaviors". In: Sustainability 12.15, p. 6023.

Pearson, A. R., M. T. Ballew, S. Naiman, and J. P. Schuldt (2017). Race, Class, Gender and Climate Change Communication. Oxford University Press. DOI: 10.1093/acrefore/9780190228620.013.412.

Pepper, G. V. and D. Nettle (2017). "The behavioural constellation of deprivation: Causes and consequences". In: Behavioral and Brain Sciences 40.

Pisano, I. and M. Lubell (2017). "Environmental Behavior in CrossNational Perspective: A Multilevel Analysis of 30 Countries". In: Environment and Behavior 49.1, pp. 31-58. DOI: 10 . 1177 / 0013916515600494.

Preacher, K. J. and A. F. Hayes (2004). "SPSS and SAS procedures for estimating indirect effects in simple mediation models". In: Behavior research methods, instruments, \& computers 36.4, pp. 717-731.

Reimers, S., E. A. Maylor, N. Stewart, and N. Chater (2009). "Associations between a one-shot delay discounting measure and age, income, education and real-world impulsive behavior". In: Personality and Individual Differences 47.8, pp. 973-978. DOI: 10.1016/j.paid.2009.07.026.

Scholten, H. et al. (2019). "Behavioral trainings and manipulations to reduce delay discounting: A systematic review". In: Psychonomic Bulletin \& Review 26.6, pp. 1803-1849.

Sheehy-Skeffington, J. and J. Rea How poverty affects People's decision-making processes.

Sommer, S., L. Mattauch, and M. Pahle (2020). "Supporting carbon taxes: The role of fairness". In: Ruhr Economic Papers.

Spence, A., W. Poortinga, and N. Pidgeon (2012). "The psychological distance of climate change". In: Risk Analysis: An International Journal 32.6, pp. 957-972.

Sze, Y. Y. et al. (2017). "Bleak present, bright future: Online episodic future thinking, scarcity, delay discounting, and food demand". In: Clinical Psychological Science 5.4, pp. 683-697.

Tanaka, T., C. F. Camerer, and Q. Nguyen (2010). "Risk and time preferences: Linking experimental and household survey data from Vietnam". In: American economic review 100.1, pp. 557-71.

Tingley, D. et al. (2014). "Mediation: R package for causal mediation analysis". In: Journal of Statistical Software 59.5.

Trotta, G. (2018). "Factors affecting energy-saving behaviours and energy efficiency investments in British households". In: Energy Policy 114, pp. 529 539 . 
van der Wal, A. J., F. van Horen, and A. Grinstein (2016). "The paradox of 'green to be seen': Green high-status shoppers excessively use (branded) shopping bags". In: International Journal of Research in Marketing 33.1, pp. 216-219. ISSN: 0167-8116. DOI: https : // doi .org/10.1016/j . ijresmar.2015.11.004.

Van Vugt, M., V. Griskevicius, and P. W. Schultz (2014). "Naturally green: Harnessing stone age psychological biases to foster environmental behavior". In: Social Issues and Policy Review 8.1, pp. 1-32.

Wang, M., M. O. Rieger, and T. Hens (Feb. 2016). "How time preferences differ: Evidence from 53 countries". In: Journal of Economic Psychology 52, pp. 115-135. ISSN: 01674870. DOI: 10.1016/j.joep.2015.12.001. 